\title{
DIABETES MELLITUS AND GESTATIONAL DIABETES MELLITUS
}

\author{
SA BEGUM ${ }^{1}$, R AFROZ ${ }^{2}$, Q KHANAM ${ }^{3}$, AKHANOM $^{4}$, T S CHOUDHURY ${ }^{5}$
}

\begin{abstract}
:
Diabetes mellitus (DM), also known as simply diabetes, is a group of metabolic diseases in which there are high blood sugar levels over a prolonged period Worldwide in 2012 and 2013 diabetes resulted in 1.5 to 5.1 million deaths per year, making it the 8th leading cause of death. Diabetes overall at least doubles the risk of death. This high blood sugar produces the symptoms of frequent urination, increased thirst, and increased hunger. Untreated, diabetes can cause many complications. Acute complications include diabetic ketoacidosis and nonketotic hyperosmolar coma. Serious long-term complications include heart disease, stroke, kidney failure, foot ulcers and damage to the eyes. The number of people with diabetes is expected to rise to 592 million by 2035 . The economic costs of diabetes globally were estimated in 2013 at $\$ 548$ billion and in the United States in $2012 \$ 245$ billion. ${ }^{[3]}$ Globally, as of 2013, an estimated 382 million people have diabetes worldwide, with type 2 diabetes making up about $90 \%$ of the cases. This is equal to $8.3 \%$ of the adults' population, with equal rates in both women and men. There are three main types of diabetes mellitus: In case of type 1 Diabetes mellitus, results from the body's failure to produce enough insulin. This form was previously referred to as "insulin-dependent diabetes mellitus" (IDDM) or "juvenile diabetes". The cause is unknown. Another type is type 2 diabetes mellitus begins with insulin resistance, a condition in which cells fail to respond to insulin properly. As the disease progresses a lack of insulin may also develop. This form was previously referred to as "non insulin-dependent diabetes mellitus" (NIDDM) or "adult-onset diabetes". The primary cause is excessive body weight and not enough exercise. Gestational diabetes is the third main form and occurs when pregnant women without a previous history of diabetes develop a high blood glucose level. Gestational diabetes usually resolves after the birth of the baby. It occurs in about $\mathbf{2 - 1 0 \%}$ of all pregnancies and may improve or disappear after delivery. However, after pregnancy approximately 5-10\% of women with gestational diabetes are found to have diabetes mellitus, most commonly type 2. Gestational diabetes is fully treatable, but requires careful medical supervision throughout the pregnancy.
\end{abstract}

Key words: Insulin-dependent diabetes mellitus" (IDDM), non insulin-dependent diabetes mellitus" (NIDDM) \& Gestational diabetes mellitus (GDM)

\section{Introduction:}

Diabetes mellitus (DM), also known as simply diabetes, is a group of metabolic diseases in which there are high blood sugar levels over a prolonged period. ${ }^{1}$ This high blood sugar produces the symptoms of frequent urination, increased thirst,

1. Dr. SA Begum, Associate Professor, Obs \& Gyne, Bangabandhu Sheikh Mujib Medical University, Dhaka

2. R Afroz, Medical officer, Obs \& Gyne, Bangabandhu Sheikh Mujib Medical University, Dhaka Dhaka

3. Q Khanam, Medical officer Obs \& Gyne, Bangabandhu Sheikh Mujib Medical University, Dhaka

4. A Khanom, Assistant Professor, Obs \& Gyne, National institute of cancer research hospital (NICRH).

5 TS Choudhury, Assistant Professor, Obs \& Gyne, BIRDEM Hospital.

Correspondence to : Dr. SA Begum, Associate Professor, Obs \& Gyne, Bangabandhu Sheikh Mujib Medical University,

Dhaka. e-mail: bsmmu@gmail.com and increased hunger. Untreated, diabetes can cause many complications. Acute complications include diabetic ketoacidosis and nonketotic hyperosmolar coma. Serious long-term complications include heart disease, stroke, kidney failure, foot ulcers and damage to the eyes. ${ }^{2}$ Worldwide in 2012 and 2013 diabetes resulted in 1.5 to 5.1 million deaths per year, making it the 8th leading cause of death. Diabetes overall at least doubles the risk of death. The number of people with diabetes is expected to rise to 592 million by 2035. The economic costs of diabetes globally were estimated in 2013 at $\$ 548$ billion and in the United States in 2012 \$245 billion. Globally, as of 2013, an estimated 382 million people have diabetes worldwide, with type 2 diabetes making up 
about $90 \%$ of the cases. This is equal to $8.3 \%$ of the adults' population, with equal rates in both women and men. [3] [4] Diabetes is due to either the pancreas not producing enough insulin, or the cells of the body not responding properly to the insulin produced. There are three main types of diabetes mellitus: In case of type 1 Diabetes mellitus, results from the body's failure to produce enough insulin. This form was previously referred to as "insulindependent diabetes mellitus" (IDDM) or "juvenile diabetes". The cause is unknown. ${ }^{5}$ Type 1 diabetes mellitus is characterized by loss of the insulinproducing beta cells of the islets of Langerhans in the pancreas, leading to insulin deficiency. This type can be further classified as immune-mediated or idiopathic as the majority of type 1 diabetes is of the immunemediated. T-cell-mediated autoimmune attack leads to the loss of beta cells and thus insulin. ${ }^{5}$ It causes approximately $10 \%$ of diabetes mellitus cases in North America and Europe. Most affected people are otherwise healthy and of a healthy weight when onset occurs. Sensitivity and responsiveness to insulin are usually normal, especially in the early stages. Type 1 diabetes can affect children or adults, but was traditionally termed "juvenile diabetes" because a majority of these diabetes cases were in children ${ }^{6}$. Brittle" diabetes, also known as unstable diabetes or labile diabetes is a term that was traditionally used to describe the dramatic and recurrent swings in glucose levels, often occurring for no apparent reason in insulin-dependent diabetes. This term, however, has no biologic basis and should not be used. [7] Another type is type 2 diabetes mellitus begins with insulin resistance, a condition in which cells fail to respond to insulin properly. As the disease progresses a lack of insulin may also develop. This form was previously referred to as "non insulindependent diabetes mellitus" (NIDDM) or "adult-onset diabetes". The primary cause is excessive body weight and not enough exercise. ${ }^{8}$

A number of lifestyle factors are known to be important to the development of type 2 diabetes, including obesity (defined by a body mass index of greater than thirty), lack of physical activity, poor diet, stress, and urbanization. [11] Excess body fat is associated with $30 \%$ of cases in those of Chinese and Japanese descent, $60-80 \%$ of cases in those of European and African descent, and $100 \%$ of Pima Indians and Pacific
Islanders. Those who are not obese often have a high waist-hip ratio. ${ }^{9}$

Dietary factors also influence the risk of developing type 2 diabetes. Consumption of sugar-sweetened drinks in excess is associated with an increased risk. The type of fats in the diet is also important, with saturated fats and trans fatty acids increasing the risk and polyunsaturated and monounsaturated fat decreasing the risk. ${ }^{29}$ Eating lots of white rice appears to also play a role in increasing risk. $A$ lack of exercise is believed to cause $7 \%$ of cases. ${ }^{[10]}$

Gestational diabetes is the third main form and occurs when pregnant women without a previous history of diabetes develop a high blood glucose level. Gestational diabetes usually resolves after the birth of the baby. ${ }^{11}$

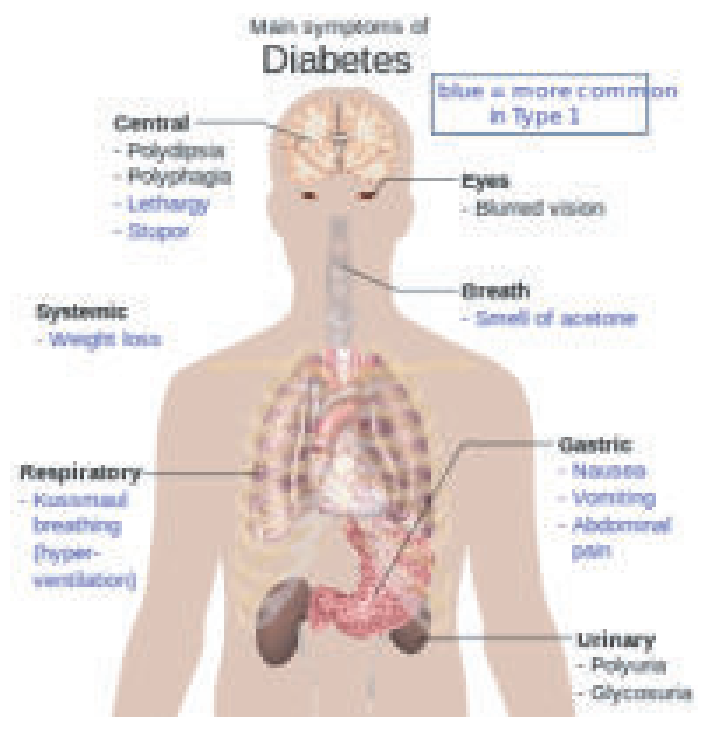

The classic symptoms of untreated diabetes are weight loss, polyuria (frequent urination), polydipsia (increased thirst), and polyphagia (increased hunger). Symptoms may develop rapidly within weeks or months in type 1 diabetes, while they usually develop much more slowly and may be subtle or absent in type 2 diabetes. ${ }^{12,13}$

Several other signs and symptoms can mark the onset of diabetes, although they are not specific to the disease. In addition to the known ones above, they include blurry vision, headache, fatigue, slow healing of cuts, and itchy skin. Prolonged high blood glucose can cause glucose absorption in the lens of the eye, which leads to changes in its shape, resulting in vision changes. A number of skin rashes that can occur in 
diabetes are collectively known as diabetic dermadromes. ${ }^{14}$

\section{Diabetic emergencies}

People usually with type 1 diabetes may also experience episodes of diabetic ketoacidosis, a type of metabolic problems characterized by nausea, vomiting and abdominal pain, the smell of acetone on the breath, deep breathing known as Kussmaul breathing, and in severe cases a decreased level of consciousness. A rare but equally severe possibility is hyperosmolar nonketotic state, which is more common in type 2 diabetes and is mainly the result of dehydration. ${ }^{15}$

All forms of diabetes increase the risk of long-term complications. These typically develop after many years like 10-20 years, but may be the first symptom in those who have otherwise not received a diagnosis before that time. The major long-term complications relate to damage to blood vessels. Diabetes doubles the risk of cardiovascular disease and about $75 \%$ of deaths in diabetics are due to coronary artery disease. Other "macrovascular" diseases are stroke, and peripheral vascular disease. ${ }^{16}$

The primary microvascular complications of diabetes include damage to the eyes, kidneys, and nerves. Damage to the eyes, known as diabetic retinopathy, is caused by damage to the blood vessels in the retina of the eye, and can result in gradual vision loss and potentially blindness. Damage to the kidneys, known as diabetic nephropathy, can lead to tissue scarring, urine protein loss, and eventually chronic kidney disease, sometimes requiring dialysis or kidney transplant. Damage to the nerves of the body, known as diabetic neuropathy, is the most common complication of diabetes. ${ }^{17}$

The symptoms can include numbness, tingling, pain, and altered pain sensation, which can lead to damage to the skin. Diabetes-related foot problems (such as diabetic foot ulcers) may occur, and can be difficult to treat, occasionally requiring amputation. Additionally, proximal diabetic neuropathy causes painful muscle wasting and weakness. There is a link between cognitive deficit and diabetes. Compared to those without diabetes, those with the disease have a 1.2 to 1.5 -fold greater rate of decline in cognitive function. ${ }^{18}$

\section{Comparison of type 1 and 2 diabetes}

\begin{tabular}{|c|c|c|}
\hline Feature & $\begin{array}{c}\text { Type } 1 \\
\text { diabetes } \\
\end{array}$ & $\begin{array}{c}\text { Type } 2 \\
\text { diabetes }\end{array}$ \\
\hline Onset & Sudden & Gradual \\
\hline Age at onset & Mostly in children & Mostly in adults \\
\hline Body size & Thin or normal & Often obese \\
\hline Ketoacidosis & Common & Rare \\
\hline Autoantibodies & Usually present & Absent \\
\hline $\begin{array}{l}\text { Endogenous } \\
\text { insulin }\end{array}$ & Low or absent & $\begin{array}{c}\text { Normal, } \\
\text { decreased or } \\
\text { increased }\end{array}$ \\
\hline $\begin{array}{l}\text { Concordance in } \\
\text { identical twins }\end{array}$ & $50 \%$ & $90 \%$ \\
\hline Prevalence & $\sim 10 \%$ & $\sim 90 \%$ \\
\hline
\end{tabular}

\section{Gestational diabetes}

Gestational diabetes mellitus (GDM) resembles type 2 diabetes in several respects, involving a combination of relatively inadequate insulin secretion and responsiveness. It occurs in about $2-10 \%$ of all pregnancies and may improve or disappear after delivery. However, after pregnancy approximately 5$10 \%$ of women with gestational diabetes are found to have diabetes mellitus, most commonly type 2 . Gestational diabetes is fully treatable, but requires careful medical supervision throughout the pregnancy. ${ }^{19}$

Gestational diabetes occurs in women who have never had diabetes. This is not a disease, but rather a temporary condition in pregnancy in which the mother's hormonal system cannot maintain normal blood sugar levels. In the United States, it is annually diagnosed in about $4 \%$ of all pregnancies about 135,000 pregnancies. It is the most common pregnancy problem. Most women with gestational diabetes have healthy babies. If blood sugar levels can be kept within a safe range, the risks to mother and baby are about the same as for a woman without it. Gestational diabetes rarely has symptoms. In rare cases, high blood sugar levels may cause increased urination and excessive thirst. ${ }^{20}$

The exact cause of gestational diabetes is unknown. Weight gain, hormonal changes, and hormones released from the placenta which block the action of insulin can cause insulin resistance. Insulin is a hormone responsible for removing glucose from the bloodstream. When insulin cannot do its job, blood sugar or glucose levels rise. When they rise high enough, gestational diabetes is diagnosed. ${ }^{21}$ 
The risk factors for gestational diabetes are as follows: Sibling or parent with diabetes, African American, Native American, Asian, Hispanic, or Pacific Islander, Over 25 years old, overweight, History of gestational diabetes, History of giving birth to multiples, a baby over 9 pounds or a baby with a birth defect, History of an unexplained miscarriage or stillbirth, Glucose in urine \&Prediabetes. In case of high risk mother glucose level must be checked at the first antenatal visit and again between 24-28 weeks of pregnancy. Usually Oral Glucose tolerance test is done to check the glucose status. In case of oral Glucose tolerance test, blood sugar is checked before the test and 2 hours after 75 gram glucose drink. Mother should be asked to remain fast for 8 hours prior to the test. ${ }^{22}$

Though it may be transient, untreated gestational diabetes can damage the health of the fetus or mother. Risks to the baby include macrosomia (high birth weight), congenital cardiac and central nervous system anomalies, and skeletal muscle malformations. Gestational diabetes is usually diagnosed later in pregnancy. The baby's body is formed, so there is not a high risk for developmental birth defects. Increased fetal insulin may inhibit fetal surfactant production and cause respiratory distress syndrome. Hyperbilirubinemia may result from red blood cell destruction. In severe cases, perinatal death may occur, most commonly as a result of poor placental perfusion due to vascular impairment. Labor induction may be indicated with decreased placental function. A Caesarean section may be performed if there is marked fetal distress or an increased risk of injury associated with macrosomia, such as shoulder dystocia. In case of mother risks are as follows: High blood pressure, increased chance for cesarean section, increased risk for Type 2 diabetes, increased risk for gestational diabetes in future pregnancies. ${ }^{23}$

Treatment plan of Gestational Diabetes should be : Meal plan with nutritional counseling if possible, moderate exercise ,self-monitoring of blood sugar levels with a blood glucose meter, insulin if needed, regular blood pressure and urine protein testing, monitoring for urine ketones if needed, Ultrasounds and non-stress tests may be used to monitor fetal well-being and growth, Kick counts to check the baby's activity, Gestational diabetes will most likely go away after delivery unless it has uncovered preexisting diabetes. Mother with gestational diabetes should be asked to return about six weeks after delivery to evaluate blood sugar levels. ${ }^{24}$
Pathophysiology: The body obtains glucose from three main places: the intestinal absorption of food, the breakdown of glycogen, the storage form of glucose found in the liver, and gluconeogenesis, the generation of glucose from non-carbohydrate substrates in the body. Insulin plays a critical role in balancing glucose levels in the body. Insulin can inhibit the breakdown of glycogen or the process of gluconeogenesis, it can stimulate the transport of glucose into fat and muscle cells, and it can stimulate the storage of glucose in the form of glycogen. ${ }^{25}$

Insulin is released into the blood by beta cells (âcells), found in the islets of Langerhans in the pancreas, in response to rising levels of blood glucose, typically after eating. Insulin is used by about twothirds of the body's cells to absorb glucose from the blood for use as fuel, for conversion to other needed molecules, or for storage. Lower glucose levels result in decreased insulin release from the beta cells and in the breakdown of glycogen to glucose. This process is mainly controlled by the hormone glucagon, which acts in the opposite manner to insulin. If the amount of insulin available is insufficient, if cells respond poorly to the effects of insulin, insulin insensitivity or insulin resistance, or if the insulin itself is defective, then glucose will not be absorbed properly by the body cells that require it, and it will not be stored appropriately in the liver and muscles. The net effect is persistently high levels of blood glucose, poor protein synthesis, and other metabolic derangements, such as acidosis. When the glucose concentration in the blood remains high over time, the kidneys will reach a threshold of reabsorption, and glucose will be excreted in the urine (glycosuria). This increases the osmotic pressure of the urine and inhibits reabsorption of water by the kidney, resulting in increased urine production (polyuria) and increased fluid loss. Lost blood volume will be replaced osmotically from water held in body cells and other body compartments, causing dehydration and increased thirst (polydipsia). ${ }^{26}$

Prevention: There is no known preventive measure for type 1 diabetes. Type 2 diabetes can often be prevented by a person being a normal body weight, physical exercise, and following a healthy diet. Dietary changes known to be effective in helping to prevent diabetes include a diet rich in whole grains and fiber, and choosing good fats, such as polyunsaturated fats found in nuts, vegetable oils, and fish. Limiting sugary beverages and eating less red meat and other sources of saturated fat can also help in the prevention of diabetes. Active smoking is also associated with an increased risk of diabetes, so smoking cessation can be an important preventive measure as well. ${ }^{27}$ 
Diagnosis: Glycated hemoglobin and Glucose tolerance test

\begin{tabular}{lccc}
\hline & \multicolumn{3}{c}{ WHO diabetes diagnostic criteria ${ }^{28,29}$} \\
\cline { 2 - 4 } Condition & $\begin{array}{c}\text { 2 hour glucose } \\
\text { Unit }\end{array}$ & Fasting glucose & $\mathrm{HbA}_{1 \mathrm{c}}$ \\
\hline Normal & $<7.8(<140)$ & $\mathrm{mmol} / /(\mathrm{mg} / \mathrm{dl})$ & $\%$ \\
Impaired fasting glycaemia & $<7.8(<140)$ & $>6.1(<110)$ & $<6.0$ \\
Impaired glucose tolerance & $>7.8(>140)$ & $<7.1(>110) \&<7.0(<126)$ & $6.0-6.4$ \\
Diabetes mellitus & $>11.1(>200)$ & $>7.0(\mathrm{e}) 126)$ & $6.0-6.4$ \\
\hline
\end{tabular}

Management: Diabetes mellitus is a chronic disease, for which there is no known cure except in very specific situations. Management concentrates on keeping blood sugar levels as close to normal ("euglycemia") as possible, without causing hypoglycemia. This can usually be accomplished with diet, exercise, and use of appropriate medications, insulin in the case of type 1 diabetes; oral medications, as well as possibly insulin, in type 2 diabetes. Learning about the disease and actively participating in the treatment is vital for people with diabetes, since the complications of diabetes are far less common and less severe in people who have well-managed blood sugar levels. The goal of treatment is an $\mathrm{HbA} 1 \mathrm{C}$ level of $6.5 \%$, but should not be lower than that, and may be set higher. Attention is also paid to other health problems that may accelerate the deleterious effects of diabetes. These include smoking, elevated cholesterol levels, obesity, high blood pressure, and lack of regular exercise.Specialized is widely used to reduce the risk of ulceration, or re-ulceration, in at-risk diabetic feet. Evidence for the efficacy of this remains equivocal, however. ${ }^{28}$

Lifestyle: People with diabetes can benefit from education about the disease and treatment, good nutrition to achieve a normal body weight, and sensible exercise, with the goal of keeping both shortterm and long-term blood glucose levels within acceptable bounds. In addition, given the associated higher risks of cardiovascular disease, lifestyle modifications are recommended to control blood pressure. $^{29}$

Anti-diabetic medication: Metformin is generally recommended as a first line treatment for type 2 diabetes, as there is good evidence that it decreases mortality. Routine use of aspirin, however, has not been found to improve outcomes in uncomplicated diabetes. Angiotensin converting enzyme inhibitors (ACEIs) improve outcomes in those with DM while the similar medications angiotensin receptor blockers (ARBs) do not. Type 1 diabetes is typically treated with a combination of regular and $\mathrm{NPH}$ insulin, or synthetic insulin analogs. When insulin is used in type 2 diabetes, a long-acting formulation is usually added initially, while continuing oral medications. Doses of insulin are then increased to effect. In those with diabetes some recommend blood pressure levels below 120/80 $\mathrm{mmHg}$; however, evidence only supports less than or equal to somewhere between 140/ $90 \mathrm{mmHg}$ to $160 / 100 \mathrm{mmHg} .^{30}$

Research: Inhaled insulin has been developed. The original products were withdrawn due to side effects. Afrezza, under development by pharmaceuticals company Mankind Corporation, was approved by the FDA for general sale in June, 2014. There are several advantages of inhaled insulin: they are convenient and easy to use and provide a useful alternative therapy for patients who cannot use intravenous insulin. ${ }^{31}$

\section{References:}

1. "Diabetes Blue Circle Symbol". International Diabetes Federation. 17 March 2006.

2. "About diabetes". World Health Organization. Retrieved 4 April 2014.

3. "Diabetes Fact sheet $\mathrm{N}^{\circ} 312$ ". WHO. October 2013. Retrieved 25 March 2014.

4. Kitabchi AE, Umpierrez GE, Miles JM, Fisher $\mathrm{JN}$. Hyperglycemic crises in adult patients with diabetes. Diabetes Care 2009; 32 (7): 1335-43.

5. Shoback, edited by David G. Gardner, Dolores (2011). “Chapter 17". Greenspan's basic \& clinical endocrinology (9th ed.). New York: McGraw-Hill Medical.

6. RSSDI textbook of diabetes mellitus. (Rev. 2nd ed.). New Delhi: Jaypee Brothers Medical Publishers. 2012. p. 235. 
7. "The top 10 causes of death Fact sheet $\mathrm{N}^{\circ}$ 310". World Health Organization. Oct 2013.

8. Rippe, edited by Richard S. Irwin, James M. Manual of intensive care medicine (5th ed.). Philadelphia: Wolters Kluwer Health/Lippincott Williams \& Wilkins. 2010. p. 49.

9. Picot J, Jones J, Colquitt JL, Gospodarevskaya E, Loveman E, Baxter L, Clegg AJ. The clinical effectiveness and cost-effectiveness of bariatric (weight loss) surgery for obesity: a systematic review and economic evaluation. Health technology assessment (Winchester, England) 2009; 13 (41): 1-190, 215-357.

10. Cash Jill. Family Practice Guidelines (3rd ed.). Springer. 2014. p. 396.

11. Williams textbook of endocrinology (12th ed.). Philadelphia: Elsevier/Saunders. pp. 1371-1435.

12. Shi Yuankai, Hu Frank B. The global implications of diabetes and cancer. The Lancet 2014; 383 (9933): 1945-2018.

13. Vos T, Flaxman AD, Naghavi M, Lozano R, Michaud C, Ezzati M, Shibuya K, Salomon JA, Abdalla $S$, Aboyans $V$, et al. Years lived with disability (YLDs) for 1160 sequelae of 289 diseases and injuries 1990-2010: a systematic analysis for the Global Burden of Disease Study 2010. Lancet. 2012; 380 (9859): 2163-96.

14. IDF DIABETES ATLAS (6th ed.). International Diabetes Federation. 2013. p. 7.

15. "International Diabetes Federation: Diabetes Atlas". Retrieved 4 April 2014.

16. American Diabetes, Association (Apr 2013). "Economic costs of diabetes in the U.S. in 2012" Diabetes Care. April 2013; 36 (4): 1033-46.

17. Cooke DW, Plotnick L. Type 1 diabetes mellitus in pediatrics. Pediatr Rev 2008; 29 (11): 374-84; quiz 385.

18. Sarwar N, Gao P, Seshasai SR, Gobin R, Kaptoge $S$, Di Angelantonio E, Ingelsson E, Lawlor DA, Selvin E, Stampfer M, Stehouwer CD, Lewington S, Pennells L, Thompson A, Sattar N, White IR, Ray KK, Danesh J . Diabetes mellitus, fasting blood glucose concentration, and risk of vascular disease: A collaborative meta-analysis of 102 prospective studies. The Lancet 2010; 375 (9733): 2215-22.
19. "Diabetes Programme." World Health Organization. Retrieved 22 April 2014.

20. Cukierman, $T$ (8Nov 2005). "Cognitive decline and dementia in diabetes-systematic overview of prospective observational studies". SpringerVerlag. Retrieved 28 Apr 2013.

21. Lambert $P$, Bingley PJ. What is Type 1 Diabetes?. Medicine 2002; 30: 1-5.

22. Dubois, HFW and Bankauskaite, Type 2 diabetes programmes in Europe. Euro Observer 2005; 7 (2): 5-6.

23. Laios K, Karamanou M, Saridaki Z, Androutsos $G$. Aretaeus of Cappadocia and the first description of diabetes. Hormones 2012; 11 (1): 109-113.

24. Oxford English Dictionary. Diabetes. Retrieved 2011-06-10.

25. Theodore $\mathrm{H}$, Tulchinsky, ElenaA. Varavikova. The New Public Health, Second Edition. New York: Academic Press. 2008. p. 200.

26. Arguedas JA, Leiva V, Wright JM. (Oct 30, 2013). "Blood pressure targets for hypertension in people with diabetes mellitus." The Cochrane database of systematic reviews.

27. "Pancreas Transplantation". American Diabetes Association. Retrieved 9 April 2014.

28. Stewart WF, Ricci JA, Chee E, Hirsch AG, Brandenburg NA. Lost productive time and costs due to diabetes and diabetic neuropathic pain in the US workforce. J. Occup. Environ. Med. June 2007; 49 (6): 672-9.

29. "Diabetes mellitus". Merck Veterinary Manual, 9th edition (online version). 2005. Retrieved 2011-1023.

30. Maria Rotella C, Pala L, Mannucci E. Role of Insulin in the Type 2 Diabetes Therapy: Past, Present and Future. International journal of endocrinology and metabolism 2013; 11 (3): 137144.

31. Piwernetz K, Home PD, Snorgaard O, Antsiferov M, Staehr-Johansen K, Krans M. Monitoring the targets of the St Vincent Declaration and the implementation of quality management in diabetes care: the DIABCARE initiative. The DIABCARE Monitoring Group of the St Vincent Declaration Steering Committee. Diabetic Medicine 1993; 10 (4): 371-7. 